\title{
A chemical sense of self in timber and prairie rattlesnakes
}

\author{
DAVID CHISZAR and HOBART M. SMITH \\ University of Colorado, Boulder, Colorado \\ CHARLES M. BOGERT \\ Museum of Southwestern Biology, University of New Mexico, Albuquerque, New Mexico \\ and \\ JASON VIDAURRI \\ University of Colorado, Boulder, Colorado
}

\begin{abstract}
Eight rattlesnakes (4 Crotalus horridus and 4 C. viridis) were observed in their home cages after the cages were thoroughly cleaned. In another trial, a patch of paper soiled by the cage inhabitant was present in the otherwise clean home cage. In a third trial, a patch of paper soiled by a conspecific was present in the otherwise clean cage. Equally high rates of lingual exploration were seen in clean cages and in cages containing conspecific chemical cues, whereas reduced rates were seen when the resident's cues were present.
\end{abstract}

Discussing husbandry at the Philadelphia Zoo, Conant (1971) mentioned that a few soiled objects (e.g., small rocks marked with excretions or secretions) were retained in otherwise cleaned reptile cages. He thought that this reduced the stress of cage cleaning, as indicated by more rapid relaxation of the occupant when a few soiled items were present than when the cage was completely clean. Motivated by this report, Chiszar and colleagues (Chiszar, Carter, Knight, Simonsen, \& Taylor, 1976; Chiszar, Wellborn, Wand, Scudder, \& Smith, 1980) observed rattlesnakes and other snakes after returning them to cleaned or uncleaned home cages. The results were consistent with Conant's views; a greater level of lingual investigation and more rapid defecation occurred when snakes were returned to cleaned home cages.

Graves and Halpern (in press), studying blue tongue skinks (Tiliqua scincoides [Shaw]), compared lingual investigation in environments that were clean, soiled by the animal being tested, and soiled by another animal. They found high rates of tongue-flicking in the clean environment and in the one soiled by a conspecific skink; but significantly lower rates were seen when the subject's own chemical cues were present. Thus, an animal's own chemical cues exerted a calming effect that was not produced by a conspecific's chemical cues. Several implications arose from these results, one of them being that $T$. scincoides can distinguish self from others on the basis of chemical information.

In the present study, we repeated the three conditions described by Graves and Halpern (in press), but the sub-

Reprints may be requested from David Chiszar, Department of Psychology, Campus Box 345, University of Colorado, Boulder, CO 80309. jects were rattlesnakes. Our goal was to begin an assessment of the generality of their findings.

\section{METHOD}

Eight adult rattlesnakes ( 2 male and 2 female prairie rattlesnakes, Crotalus viridis [Rafinesque], and 2 male and 2 female timber rattlesnakes, $C$. horridus Linnaeus; none in reproductive condition) were observed. All were long-term captives, living in individual glass cages $(50 \times 27.5 \times 30 \mathrm{~cm})$ with screen tops, paper floor covers, and stainless steel vessels filled with water. The laboratory temperature was maintained at $26^{\circ} \pm 1^{\circ} \mathrm{C}$ by electric heaters, and the photoperiod $(12: 12-\mathrm{h}$ light:dark cycle) was controlled by automatic switching devices. The snakes were fed one euthanized rat (Rattus norvegicus [Berkenhout]) or mouse (Mus musculus Linnaeus) per fortnight.

Observations were conducted once per fortnight, at least 3 days after a fecal deposit had been made on the floor cover and prior to feeding. Observation began by recording tongue flicks for $10 \mathrm{~min}$ before disturbing the snake (baseline). Then the snake was removed from its cage and placed in a holding container for $5 \mathrm{~min}$. During this period, the home cage was completely cleaned with warm water and dried with paper towels. A new paper floor cover was installed, and the stainless steel vessel was washed and refilled with water. Finally, a patch of paper $(15 \times 15 \mathrm{~cm})$ was attached to the center of the new floor cover. The patch was clean, soiled by the cage inhabitant (i.e., cut from the soiled floor cover just removed from the cage), or soiled by a conspecific (i.e., taken from a conspecific's cage that was being cleaned simultaneously; males and females were used equally often as chemical cue donors). The snake was placed again in its home cage, and tongue flicks were recorded during the next $30 \mathrm{~min}$ (see Chiszar, Radcliffe, O'Connell, \& Smith, 1981, for data on high interrater agreement in the recording of tongue flicks). Each snake received the three conditions in a randomly selected order.

\section{RESULTS}

No differences were seen between male and female subjects, and no differences were seen between prairie and timber rattlesnakes. Hence, the data were pooled across 
Table 1

Means and Standard Errors for Rates of Tongue Flicking per Minute by Rattlesnakes $(n=8)$ During Three Experimental Conditions and the Baseline Periods Preceding Them

\begin{tabular}{|c|c|c|c|c|c|c|}
\hline & \multicolumn{2}{|c|}{ Clean } & \multicolumn{2}{|c|}{$\begin{array}{c}\text { Clean + Own } \\
\text { Chemical Cues }\end{array}$} & \multicolumn{2}{|c|}{$\begin{array}{c}\text { Clean }+ \\
\text { Conspecific } \\
\text { Chemical Cues }\end{array}$} \\
\hline & $M$ & $S E$ & $M$ & $S E$ & $M$ & $S E$ \\
\hline Baseline period & $0.7 *$ & 0.3 & $0.8^{*}$ & 0.9 & $0.5^{*}$ & 0.7 \\
\hline Postcleaning & $14.6^{*}$ & 2.3 & $9.7 \dagger$ & 1.5 & $16.6^{*}$ & 4.1 \\
\hline
\end{tabular}

Note-Means within a row bearing the same superscript do not differ significantly by Wilcoxon matched-pairs signed-ranks test.

these dimensions for analysis and presentation here. Table 1 presents the mean rates of tongue-flicking during the three experimental conditions and during the baseline periods preceding them.

Baseline rates were always low, indicating that snakes were quiescent prior to cage cleaning, and the three conditions did not differ on this measure [Friedman two-way analysis of variance by ranks; $\left.\chi_{r}^{2}(2)=1.56, p>.05\right]$.

Postcleaning rates (averaged over conditions) were significantly higher than corresponding baseline averages $\left[\chi_{r}^{2}(1)=8.00, p<.05\right]$. Most important, however, was that the three conditions differed during the postcleaning period $\left[\chi_{r}^{2}(2)=4.75, .10>p>.05\right]$. The marginality of this statistic derived from one snake, and when the data were reanalyzed omitting this animal's scores, a significant effect was obtained $\left[\chi_{r}^{2}(2)=10.45, p<.01\right]$. Hence, we feel confident in rejecting the null hypothesis. (Incidentally, repeated-measures analyses of variance revealed the same pattern of outcomes as reported above.) Although rates of tongue-flicking in a clean cage did not differ from those seen in a clean cage containing a conspecific's chemical cues $\left(\chi_{r}^{2}<1\right)$, when these values were averaged, they were significantly higher than the rate seen in a clean cage containing chemical cues derived from the resident $\left[\chi_{r}^{2}(1)=3.86, p<.05\right]$.

\section{DISCUSSION}

The present results are consistent with those reported by Graves and Halpern (in press), indicating that rattlesnakes, like skinks, can distinguish a substrate soiled by themselves from a substrate soiled by conspecifics. Hence, rattlesnake excreta or secretions (cloacal, epidermal, etc.) contain signature information. No claim is made here that individual- identifying cues are used in nature, but we consider research on this issue to be a logical next step. Indeed, several lines of investigation suggest that positive results will be obtained (e.g., Brown \& MacLean, 1983; Graves, Carpenter, \& Duvall, 1987; Graves, Duvall, King, Lindstedt, \& Gern, 1986).

It should be noted that all of our snakes were tested in clean home cages with relatively small papers used to present chemical cues. Stronger effects would probably be obtained if entire floor covers and/or large porous rocks were used to present chemical cues. We consider our chemical manipulations to have been relatively subtle, and follow-up work should include stronger concentrations.

Recalling that Conant (1971) started this line of research in a husbandry context, and that his insights have led to research findings in ethology and animal learning (Chiszar et al., 1976; Chiszar et al., 1980; Wellborn, Scudder, Smith, Stimac, \& Chiszar, 1982), it is now another tribute to his intuitions that those initial observations are again leading to new discoveries, this time in chemical ecology and autecology.

\section{REFERENCES}

Brown, W. S., \& MacLean, F. M. (1983). Conspecific scent-trailing by newborn timber rattlesnakes, Crotalus horridus. Herpetologica, 39, 430-436.

Chiszar, D., Carter, T., Knight, L., Simonsen, L., \& Taylor, S. (1976). Investigatory behavior in the plains garter snake (Thamnophis radix) and several additional species. Animal Learning \& Behavior, 4, 273-278.

Chiszar, D., Radcliffe, C. W., O'Connell, B., \& Smith, H. M. (1981). Strike-induced chemosensory searching in rattlesnakes (Crotalus viridis) as a function of disturbance prior to presentation of rodent prey. Psychological Record, 31, 57-62.

Chiszar, D., Wellborn, S., Wand, M. A., Scudder, K. M., \& SMITH, H. M. (1980). Investigatory behavior in snakes: II. Cage cleaning and the induction of defecation in snakes. Animal Learning \& Behavior, 8, 505-510.

Conant, R. (1971). Reptile and amphibian management practices at Philadelphia Zoo. International Zoo Yearbook, 11, 224-230.

Graves, B. M., Carpenter, G. C., \& Duvall, D. (1987). Chemosensory behaviors of neonate prairie rattlesnakes, Crotalus viridis. Southwestern Naturalist, 32, 515-517.

Graves, B. M., Duvall, D., King, M. B., Lindstedt, S. L., \& Gern, W. A. (1986). Initial den location by neonatal prairie rattlesnakes: Functions, causes and natural history in chemical ecology. In D. Duvall, D. Müller-Schwarze, \& R. M. Silverstein (Eds.), Chemical signals in vertebrates (Vol .4, pp. 285-304). New York: Plenum Press.

Graves, B. M., \& HalPERN, M. (in press). Discrimination of self from conspecific chemical cues in Tiliqua scincoides (Sauria: Scincidae). Journal of Herpetology.

Wellborn, S., Scudder, K. M., Smith, H. M., Stimac, K., \& ChiszaR, D. (1982). Investigatory behavior in snakes: III. Effects of familiar odors on investigation of clean cages. Psychological Record, 32, 169-177.

(Manuscript received October 6, 1990.) 